\title{
Early plastic responses in the shell morphology of Acanthina monodon (Mollusca, Gastropoda) under predation risk and water turbulence
}

\author{
Maribel R. Solas ${ }^{1}$, Roger N. Hughes ${ }^{2}$, Federico Márquez ${ }^{3}$, Antonio Brante ${ }^{1, *}$ \\ ${ }^{1}$ Departamento de Ecología, Facultad de Ciencias, Universidad Católica de la Santísima Concepción, Casilla 297, \\ Concepción 4030000, Chile \\ ${ }^{2}$ Molecular Ecology and Fisheries Genetics Laboratory, School of Biological Sciences, Environment Centre Wales, \\ Bangor University, Bangor, Gwynedd LL572UW, UK \\ ${ }^{3}$ Centro Nacional Patagónico CENPAT-CONICET, Puerto Madryn U912ACD, Argentina
}

\begin{abstract}
Marine gastropods show pronounced plasticity in shell morphology in response to local environmental risks such as predation and dislodgement by waves. Previous studies have focused on juvenile and adult snails; however, adaptive plasticity might be expected to begin during embryonic and early post-embryonic stages as a means of increasing survivorship when individuals first become vulnerable. We tested the above hypothesis by measuring shell morphology of encapsulated embryos and hatchlings of Acanthina monodon exposed to predator odor and water turbulence. Subjects were assigned to 1 of 4 treatments: (1) predator odor + high water turbulence, (2) no predator odor + high water turbulence, (3) predator odor + low water turbulence, (4) no predator odor + low water turbulence (control). After approximately 1 mo, morphological traits of the shell were measured using geometric morphometrics. Hatchlings, but not encapsulated offspring, produced larger shells in the predator treatments. Encapsulated offspring and hatchlings produced thicker shells in the predator treatments, irrespective of water turbulence, whereas thinner shells were produced when high water turbulence acted alone. Even before hatching, A. monodon can, thus, respond adaptively to potential mortality factors characterizing the local external environment. Anticipating risk in this way should enhance survivorship from the point of hatching through the vulnerable juvenile phase to adulthood.
\end{abstract}

KEY WORDS: Geometric morphometrics - Direct development - Phenotypic plasticity · Morphological adaptation

\section{INTRODUCTION}

Marine gastropods are renowned for their ability to adapt their shell morphology to different environments. Although such variation may have an important additive genetic basis (Johannesson \& Johannesson 1996, Carballo et al. 2001, Conde-Padín et al. 2007, Solas et al. 2013), plasticity in response to divergent biological and physical environmental factors experienced during ontogeny is also known to be highly significant (e.g. Crothers 1983, Etter 1996,
Reid \& Osorio 2000, Sepúlveda \& Ibáñez 2012). Risk of predation and of dislodgement by waves are the 2 most frequently studied factors potentially inducing morphological changes in the shells of intertidal gastropods. Individuals living on shores where there is intense predation or reared in the laboratory under similar conditions often produce larger and thicker shells, larger apertural teeth, and smaller opercula than individuals exposed to low predation pressure (e.g. Hughes \& Elner 1979, Appleton \& Palmer 1988, Johannesson et al. 1993, Trussell \& Nicklin 2002, 
Dalziel \& Boulding 2005, Hollander \& Butlin 2010, Pascoal et al. 2012, Sepúlveda et al. 2012, Márquez et al. 2015). Similarly, individuals exposed routinely to strong wave action develop a thinner, more fusiform shell and larger operculum area, features that are correlated with higher tenacity and hydrodynamic stability (Appleton \& Palmer 1988, Johannesson et al. 1993, Márquez et al. 2015). Such morphological changes of the shell confer higher survivorship under relevant environmental conditions (Hollander \& Butlin 2010, Pascoal et al. 2012).

Most evidence of plasticity in shell morphology concerns late juveniles and adults, i.e. relatively advanced ontogenetic stages. If earlier stages can perceive appropriate environmental cues, however, it may be expected that they too should be able to modify shell morphology. By doing so, individuals should promote survivorship not only of hatchlings, but also of subsequent stages by advancing the process of locally adaptive phenotypic plasticity. For example, free-swimming veliger larvae of the intertidal snail Littorina scutulata develop smaller shell apertures and rounder shells when cultivated in the presence of predatory zoea larvae of Cancer spp., gaining higher survivorship than controls (Vaughn 2007). Many marine gastropods, however, protect their larvae or embryos within jelly masses or egg capsules, which may constrain their ability to sense the external environment. Nevertheless, 2 lines of evidence suggest that enclosed offspring may indeed respond to external stimuli. First, larvae of the gastropod Nucella lamellosa respond to extracapsular stimuli emanating from crustacean predators by delaying hatching time (Miner et al. 2010). Certain frog larvae respond to ambient vibration generated by mobile predators by hatching earlier from the jelly mass (Warkentin 1995, 2005). Second, experiments with stable isotopes suggest that the capsule wall of the gastropod Crepidula fornicata may be permeable to dissolved organic material (Leroy et al. 2012).

The muricid gastropod Acanthina monodon (Pallas, 1774) inhabits the intertidal rocky shore and shallow subtidal of the Chilean coast from $28^{\circ}$ to $55^{\circ} \mathrm{S}$ (Gallardo 1979). Female A. monodon enclose their offspring in capsules attached to hard substrata. The number of eggs per capsule is variable and may fluctuate between 300 and >1000 (Lardies \& Fernández 2002). Most of the eggs are nurse eggs, and only $10 \%$ hatch as juveniles of approximately 0.82 to $1.3 \mathrm{~mm}$ shell length after 60 to $80 \mathrm{~d}$ of intracapsular development (Gallardo \& Garrido 1987). Adults may reach more than $4.0 \mathrm{~cm}$ in shell length (Gallardo 1979). Shell shape, color, and thickness are highly polymor- phic (Sánchez et al. 2011, Sepúlveda et al. 2012). Shell morphology and size have intermediate to high heritability (Solas et al. 2013), suggesting that although these traits have an additive genetic basis, variation also results from phenotypic plasticity. Shell morphology of A. monodon is influenced by predation risk and wave exposure (Sepúlveda et al. 2012, Solas et al. 2013). Laboratory studies show that maturing juveniles thicken the shell in the presence of predator exudates (Sepúlveda et al. 2012), and field observations (M. R. Solas and A. Brante pers. obs.) suggest that they may respond to wave exposure by developing a larger operculum area and thinner shell.

Using geometric morphometrics (Bookstein 1991, Rohlf 2005a), we evaluated the capacity of encapsulated larvae and newly hatched juveniles of $A$. monodon to modify shell morphology in response to predator odor and water turbulence in a factorial laboratory experiment.

\section{MATERIALS AND METHODS}

\section{Study area and sample collection}

During spring 2013, approximately 600 egg capsules from at least 50 clutches were haphazardly collected from the intertidal rocky shore at Desembocadura del Río Bío-Bío, Chile $\left(36^{\circ} 48^{\prime} 23.07^{\prime \prime}\right.$ S, $73^{\circ} 10^{\prime}$ $\left.36.17^{\prime \prime} \mathrm{W}\right)$. All capsules contained eggs still at the pre-segmentation stage. At this early stage in development, capsules are bright yellow, later becoming duller in coloration. Developmental stage was confirmed using a binocular microscope. Capsules were stored, labeled according to clutch, and transported to the Estación de Biología Marina Abate Molina of the Universidad Católica de la Santísima Concepción. Clutches were pooled before assigning capsules to experimental treatments.

\section{Shell plasticity in response to predator odor and water turbulence}

Pre-hatching individuals

Capsules containing eggs were cultivated in plastic bottles that were perforated and covered with mesh of $100 \mu \mathrm{m}$ pore size to allow circulation of ambient seawater. Capsules were assigned to 4 treatments: (1) presence of predators + high water turbulence (PP-HT), (2) absence of predators + high 
water turbulence (AP-HT), (3) presence of predators + low water turbulence (PP-LT), (4) absence of predators + low water turbulence (AP-LT, control). For the predator treatments, 24 individuals of the crab Homalaspis plana (H. Milne Edwards) were individually caged and spaced equally apart in a fiberglass tank of approximately $4.0 \times 1.5 \times 0.5 \mathrm{~m}$. Bottles containing egg capsules were placed between the crab cages, allowing predator exudates to bathe the egg capsules. A second tank identical to the above but lacking crabs was set up as a control. In both tanks, bottles were relocated from time to time to avoid position effects. Lack of space precluded replication of tanks. To simulate traction force and water turbulence at low and high wave strength, air stones were used to generate gentle or intense bubbling within bottles. To ensure high levels of traction through bubbling, air pressure was carefully increased and maintained at the level just before dislodgement of post-hatching individuals was observed. The base of each capsule was fixed to the bottom of the bottle by a small drop of cyanoacrylate adhesive. Four bottles each containing 20 egg capsules were assigned per treatment. Experimental aquaria were filled with continuously flowing unfiltered seawater at approximately 35 ppm salinity and $14 \pm 1^{\circ} \mathrm{C}$. When individuals within capsules reached the pre-hatching stage (shell size approximately $1 \mathrm{~mm}), 16$ individuals per bottle were randomly selected and fixed in $95 \%$ ethanol for morphometric analysis.

\section{Post-hatching individuals}

In order to evaluate plastic responses in the shells of newly hatched individuals, 20 capsules containing eggs at the pre-segmentation stage were cultivated in the control treatments (AP-LT) until hatching. Newly hatched juveniles (shell size approximately $1.0-1.5 \mathrm{~mm}$ ) were pooled and allocated to the 4 treatments described above. Four plastic boxes, each containing 20 individuals, were allocated per treatment. Boxes were perforated, covered with mesh of $100 \mu \mathrm{m}$ pore size to allow circulation of ambient seawater, and positioned in fiberglass tanks as described above for pre-hatching individuals. Post-hatching snails were fed with the mussels Semimytilus algosus (Gould) and Perumytilus purpuratus (Lamarck) and maintained in each treatment for 2 mo. After completing the experiment, 16 individuals per box were randomly selected and fixed in $95 \%$ ethanol for morphometric analysis.

\section{Morphometric analysis}

Shells were photographed under a binocular microscope in ventral aspect, keeping the aperture plane in horizontal position in all cases and at constant magnification $(4 \times)$. Images were analyzed using geometric morphometrics (GM; Zelditch et al. 2004). Fourteen landmarks were placed on the shells of pre-hatching individuals (Fig. 1A) and 18 on
Fig. 1. Morphological landmark positions on the ventral aspect of the shell of Acanthina monodon: (A) pre-hatching stage (14 landmarks), (B) hatchling stage (18 landmarks). See 'Materials and methods' for further landmark descriptions

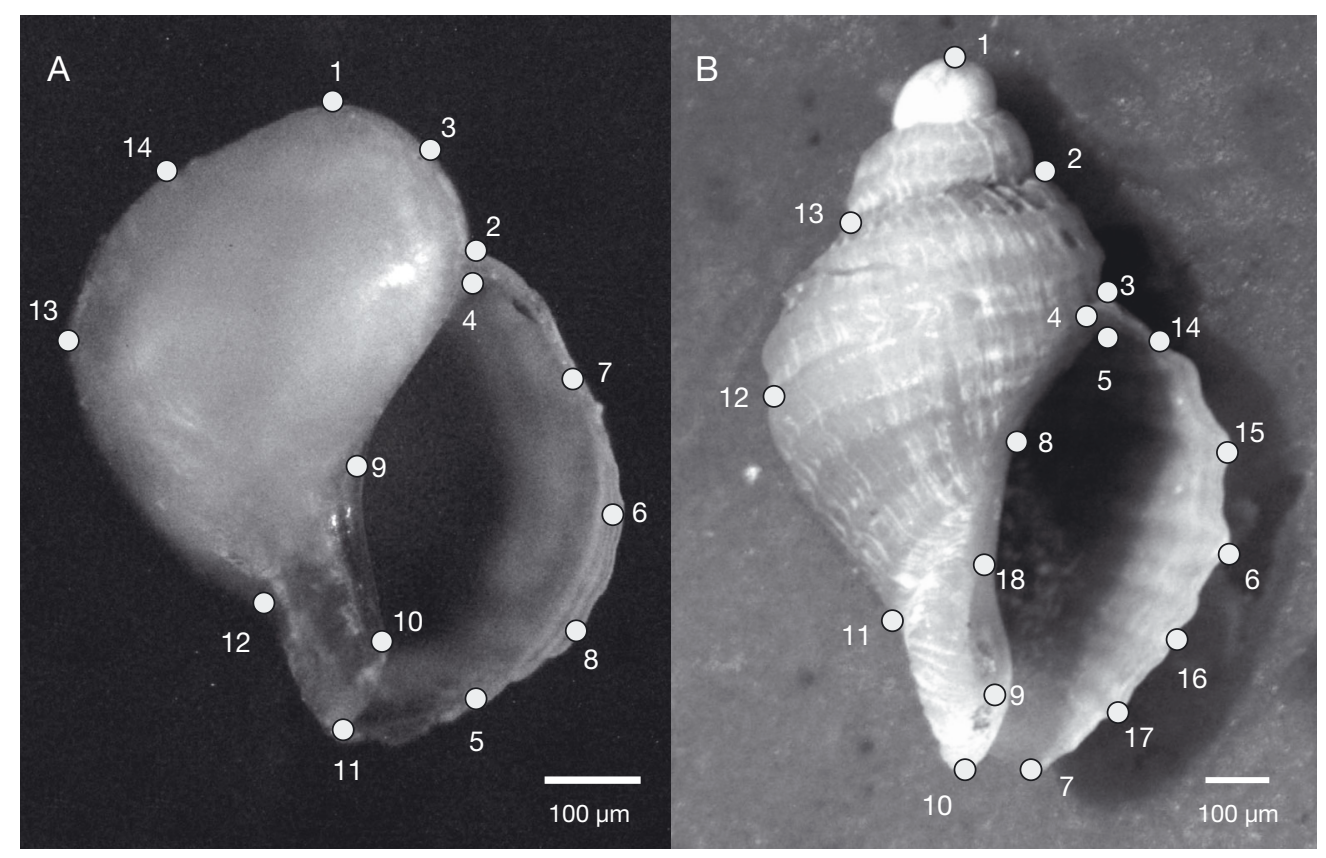


hatchlings (Fig. 1B), defining the positions of specific anatomical characters and geometrical properties of the shell. Three types of landmarks with the following criteria were used: (1) type I landmarks are anatomical points whose supposed homology is based on biological evidence; (2) type II are mathematical points based solely on the geometry and not on anatomical evidence; these landmarks usually include reference positions (e.g. points of maximum curvature; Bookstein 1991); and (3) type III are those located anywhere along an edge or between 2 anatomical or mathematical landmarks; these are thus known as built or semi-landmarks. Landmarks were distributed mainly in the area of the operculum, outer coil area, and the intersection area between the outer and inner lip corresponding to the anal canal (i.e. landmarks [LM] 2 and 4). Thus 7 morphological type I landmarks $(1,2,4,5,10,11,12), 5$ type II $(3,6$, $9,13,14)$, and 2 type III ( 7 and 8 ) were placed on the shells of pre-hatching individuals of Acanthina monodon (Fig. 1A). Of the 18 landmarks placed on the shells of post-hatching juveniles, 12 were type I landmarks $(1-5,7-11,13,18), 2$ type II $(6,12)$, and 4 type III (14-17; Fig. 1B). Similar landmarks were used by Sánchez et al. (2011), Sepúlveda \& Ibáñez (2012), and Solas et al. (2013). Landmarks were digitalized using tpsDig2 software (Rohlf 2005b).

To obtain optimal shape variables, called relative warps (RW), the aligned specimens were compared through tpsRelw (Rohlf 2005c) using alpha $=1$, which weights the most remote landmarks producing a global deformation effect in the snails. All RWs are orthogonal components, and therefore contain independent variance, analogous to a principal component analysis. Finally, centroid size (CS) was used as a proxy of the shell size of individuals, and was determined using tpsRelw (Rohlf 2005c). CS corresponds to a dispersion measure of landmarks around the centroid and is computed as the square root of the sum of squared distances of all landmarks from the centroid.

\section{Statistical analysis}

CS was compared for pre- and post-hatching individuals using permutational ANOVA (PERMANOVA) with water turbulence (intense or gentle bubbling, i.e. high or low turbulence) and predation risk (with or without predator odor) as fixed factors. Bottle (for pre-hatching experiments) or box (for post-hatching experiments) were nested random factors. RWs (RWI and RWII) explaining most of the mor- phological variation (see 'Results') were analyzed using permutational analysis of covariance (PERMANCOVA) with $\log (\mathrm{CS})$ as the covariate, water turbulence and predation risk as fixed factors, and bottle or box as nested random factors; 10000 permutations were used. Post hoc pairwise comparisons were performed when appropriate. Analyses were run using the software PRIMER 6 (PRIMER-E).

\section{RESULTS}

\section{Pre-hatching individuals}

Mean shell size was ranked among treatments as PP-HT < AP-LT < PP-LT < AP-HT (Fig. 2A). Significant interaction between water turbulence and predation risk (Table 1) precluded comparison of levels within factors. Pairwise comparisons therefore

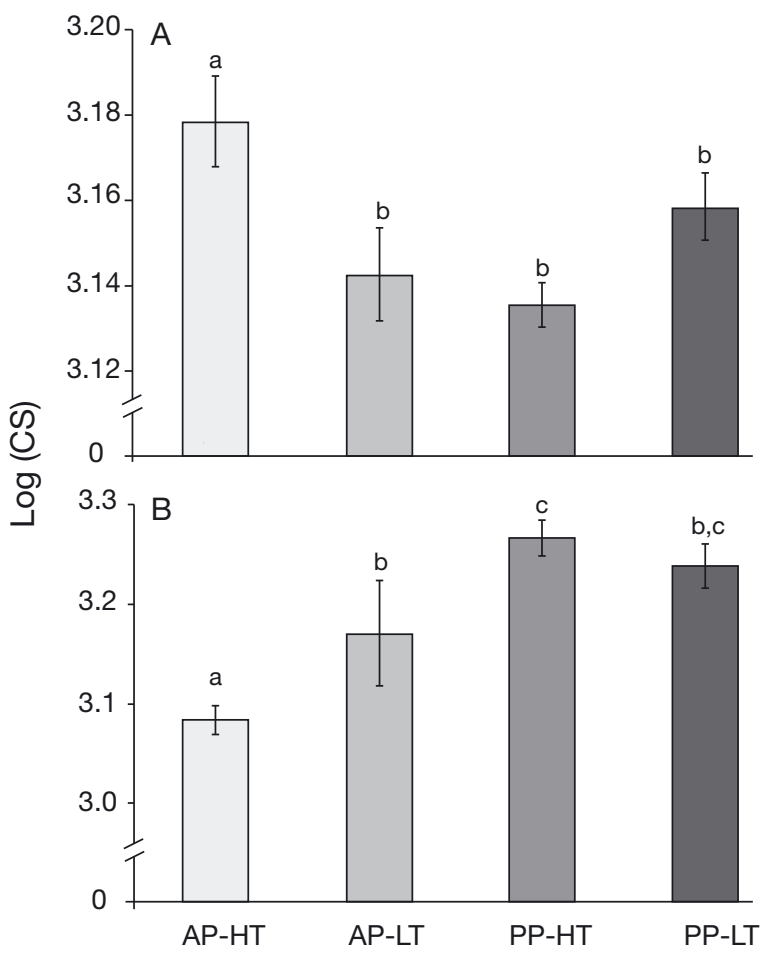

Fig. 2. Logarithm of centroid size $\left(C S_{\text {; }}\right.$ mean $\left.\pm \mathrm{SE}\right)$ as an estimator of shell size of Acanthina monodon at (A) pre-hatching and (B) post-hatching juvenile stages exposed to different experimental conditions: (1) absence of predators + high water turbulence (AP-HT), (2) absence of predator + low water turbulence (AP-LT, control), (3) presence of predators + high water turbulence (PP-HT) and (4) presence of predators + low water turbulence (PP-LT). Letters above the bars represent statistical significance of pairwise comparisons (different letters show significant differences at $\mathrm{p}<0.05$ ) 
Table 1. Permutational MANOVA of log(centroid size) as a measure of shell size for pre-hatching juveniles of Acanthina monodon exposed to different experimental conditions. T: water turbulence, P: predator odor, B: bottle. Significant results $(p<0.05)$ are in bold

\begin{tabular}{|lccccc|}
\hline & SS & df & MS & $F$ & $\mathrm{p}$ \\
\hline $\mathrm{T}$ & 0.012 & 1 & 0.012 & 2.538 & 0.138 \\
$\mathrm{P}$ & 0.003 & 1 & 0.003 & 0.577 & 0.458 \\
$\mathrm{~T} \times \mathrm{P}$ & 0.058 & 1 & 0.058 & 12.650 & $\mathbf{0 . 0 0 6}$ \\
$\mathrm{B}(\mathrm{T} \times \mathrm{P})$ & 0.055 & 12 & 0.004 & 4.002 & $\mathbf{0 . 0 0 1}$ \\
Residual & 0.335 & 240 & 0.001 & & \\
\hline
\end{tabular}

Table 2. Permutational analysis of covariance of scores on the first 2 relative warps (RWI and RWII) for pre-hatching juveniles of Acanthina monodon exposed to different experimental conditions. T: water turbulence, P: predator odor, CS: centroid size, B: bottle. Significant results $(p<0.05)$ are in bold

\begin{tabular}{|lrrrrr|}
\hline & SS & df & MS & $F$ & $\mathrm{p}$ \\
\hline RWI & & & & & \\
log-CS (covariate) & 0.009 & 1 & 0.009 & 20.259 & $\mathbf{0 . 0 0 1}$ \\
$\mathrm{T}$ & 0.001 & 1 & 0.001 & 0.703 & 0.433 \\
$\mathrm{P}$ & 0.000 & 1 & 0.000 & 0.147 & 0.693 \\
$\mathrm{P} \times \mathrm{T}$ & 0.000 & 1 & 0.000 & 0.502 & 0.478 \\
$\mathrm{~B}(\mathrm{P} \times \mathrm{T})$ & 0.011 & 12 & 0.001 & 3.191 & $\mathbf{0 . 0 0 1}$ \\
Residual & 0.064 & 224 & 0.000 & & \\
RWII & & & & & \\
log-CS (covariable) & 0.006 & 1 & 0.006 & 25.152 & $\mathbf{0 . 0 0 1}$ \\
$\mathrm{T}$ & 0.003 & 1 & 0.003 & 14.120 & $\mathbf{0 . 0 0 3}$ \\
$\mathrm{P}$ & 0.001 & 1 & 0.001 & 6.467 & $\mathbf{0 . 0 2 7}$ \\
P $\times \mathrm{T}$ & 0.001 & 1 & 0.001 & 2.413 & 0.145 \\
$\mathrm{~B}(\mathrm{P} \times \mathrm{T})$ & 0.003 & 12 & 0.000 & 0.805 & 0.651 \\
Residual & 0.059 & 224 & 0.000 & & \\
\hline
\end{tabular}

were made between treatments. Shells were significantly larger in AP-HT than in any other treatment (Fig. 2A).

Morphological variation of the shell (Fig. 3A) was largely explained by the first 2 RWs (RWI: $33.52 \%$, RWII: 28.52\%). LM2 (eigenvector RWI = 60.91, eigenvector RWII $=-307.15$ ) and LM4 (eigenvector RWI $=-117.43$; RWII $=364.67$ ) were the most important contributors to morphological variation. Variation in LM2 occurred on the $y$-axis for both RWs, while variation in LM4 occurred on the $x$-axis for RWI and on the $y$-axis for RWII. Both landmarks were associated with thickness of the shell (Fig. 1A).

PERMANCOVA of scores on RWI showed no significant terms, whereas for RWII, water turbulence and predation risk, but not their interaction, were significant (Table 2). Scores on RWII showed that the
Table 3. Permutational ANOVA of $\log$ (centroid size) as a measure of shell size hatchlings of Acanthina monodon exposed to different experimental conditions. T: water turbulence, P: predator odor, B: bottle. Significant results $(\mathrm{p}<0.05)$ are in bold

\begin{tabular}{|lccccc|}
\hline & SS & df & MS & $F$ & $\mathrm{p}$ \\
\hline $\mathrm{T}$ & 0.429 & 1 & 0.429 & 12.404 & $\mathbf{0 . 0 0 4}$ \\
$\mathrm{P}$ & 0.012 & 1 & 0.012 & 0.360 & 0.558 \\
$\mathrm{~T} \times \mathrm{P}$ & 0.489 & 1 & 0.489 & 14.118 & $\mathbf{0 . 0 0 5}$ \\
$\mathrm{B}(\mathrm{T} \times \mathrm{P})$ & 0.392 & 12 & 0.033 & 11.006 & $\mathbf{0 . 0 0 3}$ \\
Residual & 0.842 & 240 & 0.003 & & \\
& & & & & \\
\hline
\end{tabular}

thinnest shells were produced under high turbulence in the absence of predator odor (treatment AP-HT) and the thickest shells in the presence of predator odor under low turbulence (PP-LT; Fig. 4A). Pairwise comparison between treatments showed that shells were significantly thinner in the presence of predator odor under high turbulence (PP-HT) than in the presence of predator odor under low turbulence (PP-LT) and significantly thinner in the absence of predator odor under high turbulence (AP-HT) than in the absence of predator odor under low turbulence (APLT) (Fig. 4A).

\section{Post-hatching individuals}

Mean shell size was ranked among treatments as AP-HT < AP-LT < PP-LT < PP-HT (Fig. 2B). Interaction between water turbulence and predation risk was statistically significant (Table 3). Pairwise comparisons showed that shells in treatment AP-HT were significantly smaller than in any other treatment and smaller in treatment AP-LT than in PP-HT but not PPLT (Fig. 2B). No significant differences were observed between the 2 treatments that showed the bigger shell sizes (PP-HT and PP-LT; Fig. 2B).

Morphological variation of the shell was largely explained by the first 2 RWs (RWI: 30.82\%, RWII: $24.88 \%$; Fig. 3B). Major variation in shell morphology occurred along the RWI axis, involving treatments with or without predator odor. Differences in RWI scores were attributable mainly to variation in LM3 on the $x$-axis (eigenvector RWI $=299.6$ ) and LM5 on the $x$-axis (eigenvector RWI $=-609.8$ ). For RWII, landmarks with greatest variation were LM4 on the $x$-axis (eigenvector $=199.25$ ) and LM5 on the $y$-axis (eigenvector $=-262.6$ ). As in pre-hatching individuals, LM3, LM4, and LM5 were associated with the thickness of the shell (Fig. 1B). 

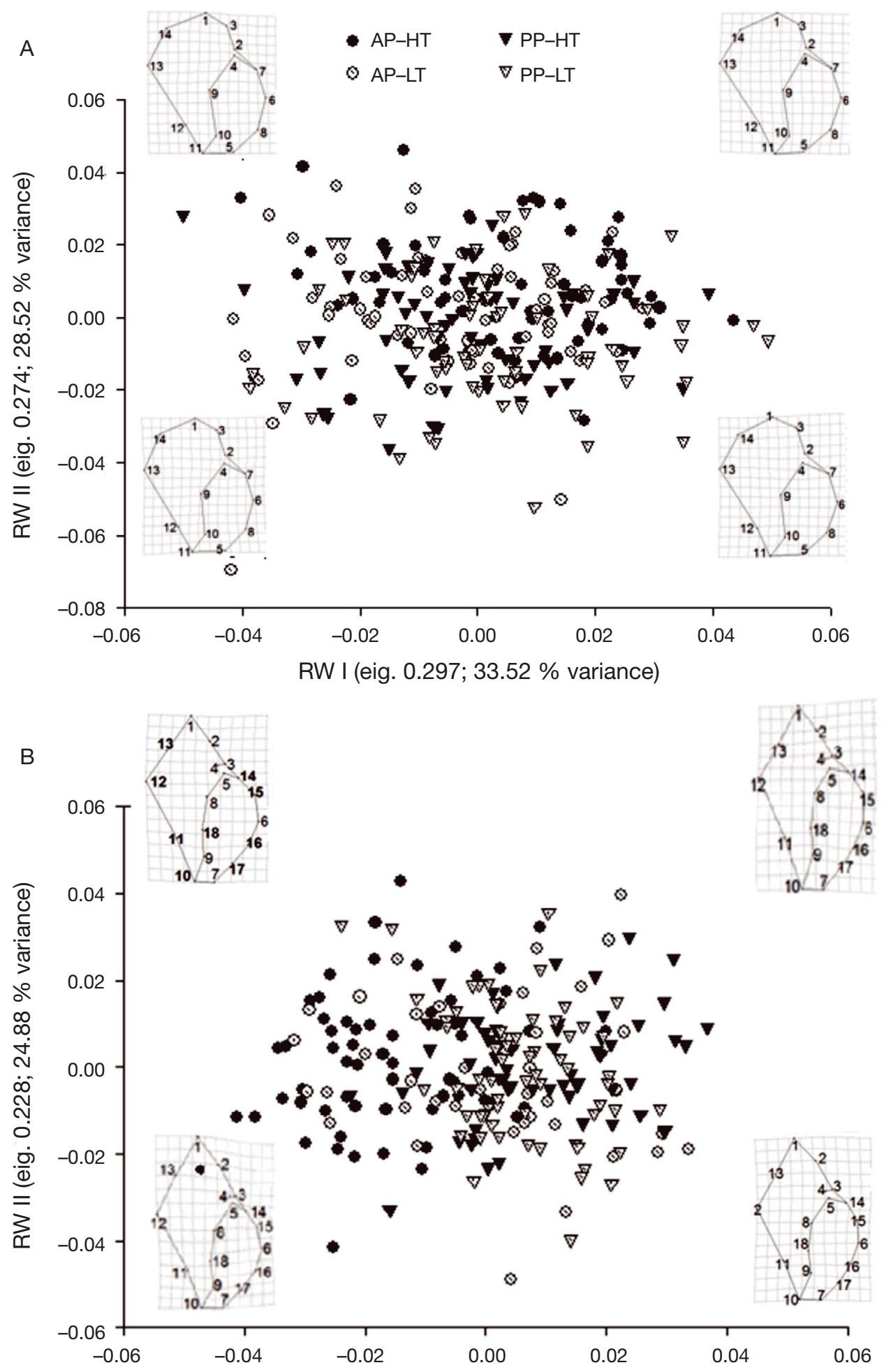

RW I (eig. 0.254; $30.82 \%$ variance)

Fig. 3. Principal components analysis of relative warp (RW) scores representing shell morphology of Acanthina monodon at (A) pre-hatching stage and (B) hatchling stage exposed to different experimental conditions (as defined in Fig. 2). The eigenvalues (eig.) and the percentage variance explained by each RW are given in the axis labels. Thin-plate spline representations of snail shells are included for extremes of the gradient for the first 2 RWs. Some landmarks are connected by lines to facilitate 

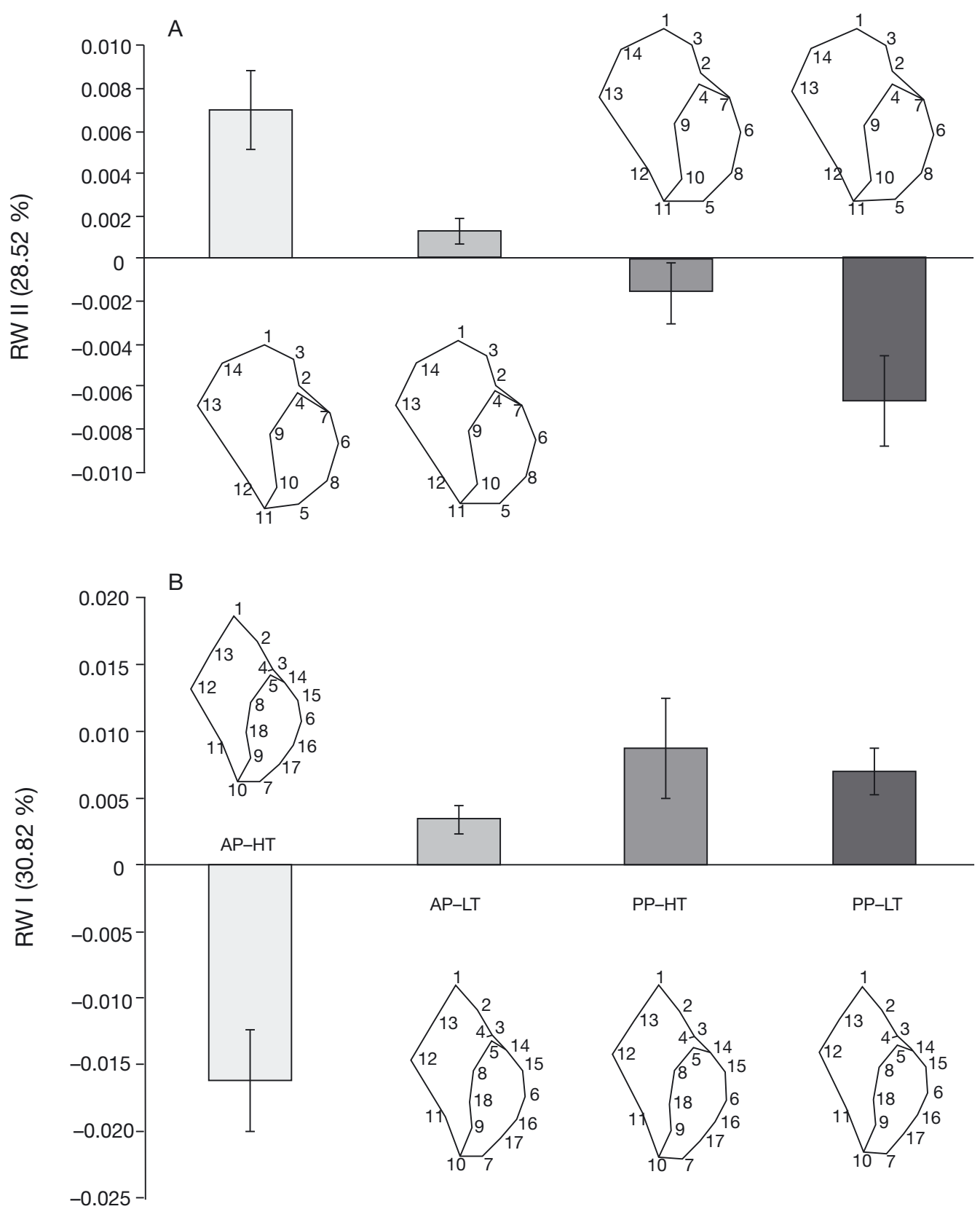

Fig. 4. Mean ( \pm SE) relative warp (RWI and RWII) scores for (A) pre-hatching stage and (B) hatchling stage of Acanthina monodon exposed to different experimental conditions (as defined in Fig. 2). PP-HT: presence of predators + high water turbulence; AP-HT: absence of predators + high water turbulence; PP-LT: presence of predators + low water turbulence; AP-LT (control): absence of predator + low water turbulence. Consensus thin-plate spline representations of snail shells are included for each treatment

PERMANCOVA of RWI scores showed significant water turbulence $\times$ predation risk interaction, but there were no significant terms for RWII (Table 4). Thicker shells were formed in the presence of predator odor with low turbulence and thinner shells under high turbulence without predator odor (Fig. 4B). Shell thickness was similar when predator odor was present either with high or low turbulence (Fig. 4B).

\section{DISCUSSION}

The above results show that Acanthina monodon is able to initiate phenotypic plasticity in response to factors associated with water turbulence and predation risk very early in ontogeny, even prior to hatching. Plasticity is expressed mainly in shell size and thickness. 
Table 4. Permutational analysis of covariance of scores on the first 2 relative warps (RWI and RWII) for hatchlings of Acanthina monodon exposed to different experimental conditions. T: water turbulence, P: predator odor, CS: centroid size, B: bottle. Significant results $(p<0.05)$ are in bold

\begin{tabular}{|lccccc|}
\hline & SS & df & MS & $F$ & $\mathrm{p}$ \\
\hline RWI & & & & & \\
log-CS (covariate) & 0.014 & 1 & 0.014 & 30.093 & $\mathbf{0 . 0 0 1}$ \\
T & 0.006 & 1 & 0.006 & 9.834 & $\mathbf{0 . 0 1 0}$ \\
P & 0.002 & 1 & 0.002 & 3.830 & 0.071 \\
P $\mathrm{T}$ & 0.004 & 1 & 0.004 & 8.115 & $\mathbf{0 . 0 1 3}$ \\
B(P×T) & 0.007 & 11 & 0.001 & 3.971 & $\mathbf{0 . 0 0 1}$ \\
Residual & 0.064 & 224 & 0.000 & & \\
RWII & & & & & \\
log-CS (covariate) & 0.001 & 1 & 0.001 & 1.701 & 0.206 \\
T & 0.000 & 1 & 0.000 & 0.347 & 0.564 \\
P & 0.000 & 1 & 0.000 & 0.225 & 0.644 \\
P $\times$ T & 0.001 & 1 & 0.001 & 1.088 & 0.313 \\
B(P×T) & 0.009 & 11 & 0.001 & 4.318 & $\mathbf{0 . 0 0 1}$ \\
Residual & 0.059 & 224 & 0.000 & & \\
\hline
\end{tabular}

Shell size is known to be strongly correlated to survivorship of early life stages of several marine gastropods (e.g. Ito 1997, Moran \& Emlet 2001). In the present study, pre-hatching individuals of A. monodon developed the largest shell under high water turbulence without predator cues. This is consistent with field observations of the confamilial Nucella ostrina, in which larger shells have been recorded in hatchlings from sites with high wave exposure and low predation risk (Gosselin \& Rehak 2007). On the other hand, Etter (1989) found that hatchlings of $N$. lapillus were larger on wave-protected than on wave-exposed shores. These contradictory results and the different response patterns we observed between pre- and post-hatching juveniles (see below) suggest that multiple interacting factors, such as food availability, intracapsular oxygen concentration, and larval competition, may influence shell growth within the capsule (e.g. Spight 1976, Lardies \& Fernández 2002, Brante et al. 2009). In contrast to encapsulated individuals, however, hatchlings generally developed bigger shells in the presence of predator odor independently of the degree of water turbulence. Our results for hatchlings, therefore, are consistent with those reported for a variety of other marine gastropods. For example, it has been observed that juveniles and adults of Littorina spp., Nucella spp., Trophon spp., and A. monodon tend to show greater shell sizes in environments with intense predation risk than those experiencing low predation risk (Hughes \& Elner 1979, Appleton \& Palmer 1988, Johannesson et al. 1993, Dalziel \& Boulding 2005,
Hollander \& Butlin 2010, Pascoal et al. 2012, Sepúlveda et al. 2012, Márquez et al. 2015). On the other hand, the smaller shell size of hatchlings that we cultivated in high water turbulence without predation stimuli could represent an adaptive response to the risk of dislodgement, if small size reduces drag forces generated by high water turbulence or allows access to shelter within small crevices or inside the mantle cavity of mussels (Hohenlohe 2003).

Shell thickness is well known to be correlated with survivorship in habitats harboring durophagous predators. We observed that thicker shells were produced both by pre- and post-hatching juveniles of $A$. monodon when exposed to exudates of the predatory crab Homalaspis plana. Unfortunately, lack of tank replication compromised statistical analysis. However, the similar physical characteristics and cultivation parameters (temperature, water flow, light, etc.) in both tanks, and the similar results observed in comparison to those reported for later ontogenetic stages of several other gastropods (Hughes \& Elner 1979, Appleton \& Palmer 1988, Johannesson et al. 1993, Dalziel \& Boulding 2005, Hollander \& Butlin 2010, Pascoal et al. 2012, Sepúlveda et al. 2012, Márquez et al. 2015) suggest that the morphological differences observed in shells are more likely attributable to predator stimuli than to tank effects. Adults from wave-exposed sites lacking predators are generally reported to have thin (but see Pascoal et al. 2012), fusiform shells with a larger operculum area (Appleton \& Palmer 1988, Johannesson et al. 1993, Trussell 1997, Márquez et al. 2015), and such observations are consistent with our results for pre- and post-hatching stages in treatments with turbulence but no predation cue.

Interestingly, in both pre- and post-hatchlings, shell thickness in the treatment with predator odor and high turbulence was more similar to that in the treatment with predator odor and low turbulence than in the treatment with no predator odor and low turbulence (Fig. 4). Two alternative explanations of this pattern may be suggested. First, the shell response observed in the interaction treatment may be attributed to a lower turbulence level used for our experiments in comparison to that experienced in the field, preventing plastic responses. However, changes observed in the shell morphology of $A$. monodon when the turbulence factor acted alone suggest that the turbulence level used was enough to trigger plastic responses in this species. A second explanation for the pattern observed is that predation is a more powerful selective force than turbulence. Miller et al. (2007) showed that dislodgement of individual Littorina 
keenae from the intertidal was not necessarily lethal, since many returned to their original place on the shore. In addition, Hohenlohe (2003) observed in wave-exposed intertidal habitats that small individuals of Littorina spp. may use crevices or interstices of intertidal mussel beds for protection against strong wave action. However, both microenvironments also serve as shelters for predatory crabs, which may increase the mortality rate of juvenile snails (e.g. Navarrete \& Castilla 1990, Thiel \& Dernedde 1994). In such cases, phenotypic responses to predation risk might be favored over responses to risk of dislodgement by waves when both factors act simultaneously.

Surprisingly, we did not observe any increase in operculum area of pre- or post-hatching individuals exposed to high turbulence. A larger operculum area, often reported from shores exposed to higher wave action, is correlated with larger pedal area and gripping power, and hence with greater tenacity (e.g. Johannesson et al. 1993, Pascoal et al. 2012, Márquez et al. 2015). Lack of plasticity in operculum area among our experimental subjects may suggest alternative mechanisms that increase tenacity in environments with high turbulence. For example, L. obtusata increases size of the pedal foot muscle, which increases tenacity without any apparent change in operculum area (Trussell 1997). A similar mechanism could apply to A. monodon, and future work should consider this possibility.

Even before hatching from the egg capsule, $A$. monodon can respond adaptively to potential mortality factors characterizing the local external environment by initiating phenotypic plasticity. Anticipating risk in this way should enhance survivorship from the point of hatching through the vulnerable juvenile phase to adulthood. Our results are consistent with those observed in adult and juvenile snails of other species (e.g. Hollander \& Butlin 2010), suggesting that such responses in marine gastropods represent adaptive peaks as a result of co-action between additive genetic variance and plasticity throughout ontogeny (Agrawal 2001, Agrawal et al. 2002).

Acknowledgements. We are especially grateful to $\mathrm{R}$. González-José for support and to P. Solas-Hugo for help in field and laboratory work. M.S. is grateful for tuition remission, stipend, and teaching assistance fellowships, granted by the Master Program of Marine Ecology of the Universidad Católica de la Santísima Concepción. We thank Roger Sepúlveda for assistance with statistical analyses. This study was funded by Fondo Nacional de Desarrollo Científico y Tecnológico (FONDECYT) grant no. 1130868 to A.B. and by the Concurso Atracción de Capital Humano Avanzado del Extranjero, Modalidad de Estadías Cortas (MEC) no. 80122001 to A.B. and R.N.H.

\section{LITERATURE CITED}

Agrawal AA (2001) Phenotypic plasticity in the interactions and evolution of species. Science 294:321-326

> Agrawal AA, Conner JK, Johnson MT, Wallsgrove R (2002) Ecological genetics of an induced plant defense against herbivores: additive genetic variance and costs of phenotypic plasticity. Evolution 56:2206-2213

Appleton RD, Palmer AR (1988) Water-borne stimuli released by predatory crabs and damaged prey induce more predator-resistant shells in a marine gastropod. Proc Natl Acad Sci USA 85:4387-4391

Bookstein FL (1991) Morphometric tools for landmark data. Cambridge University Press, New York, NY

> Brante A, Fernandez M, Viard F (2009) Limiting factors to encapsulation: the combined effects of dissolved protein and oxygen availability on embryonic growth and survival of species with contrasting feeding strategies. J Exp Biol 212:2287-2295

Carballo M, Garcia C, Rolán-Alvarez E (2001) Heritability of shell traits in wild Littorina saxatilis populations: results across a hybrid zone. J Shellfish Res 20:415-422

Conde-Padín P, Carvajal-Rodriguez A, Carballo M, Caballero A, Rolan-Alvarez E (2007) Genetic variation for shell traits in a direct-developing marine snail involved in a putative sympatric ecological speciation process. Evol Ecol 21:635-650

> Crothers JH (1983) Variation in dog-whelk shells in relation to wave action and crab predation. Biol J Linn Soc 20:85-102

Dalziel B, Boulding G (2005) Water-borne cues from a shellcrushing predator induce a more massive shell in experimental populations of an intertidal snail. J Exp Mar Biol Ecol 317:25-35

> Etter RJ (1989) Life history variation in the intertidal snail Nucella lapillus across a wave-exposure gradient. Ecology 70:1857-1876

- Etter RJ (1996) The effect of wave action, prey type, and foraging time on growth of the predatory snail Nucella lapillus. J Exp Mar Biol Ecol 196:341-356

Gallardo C (1979) Developmental pattern and adaptations for reproduction in Nucella crassilabrum and other muricacean gastropods. Biol Bull (Woods Hole) 157:453-463

Gallardo CS, Garrido O (1987) Nutritive egg formation in the marine snails Crepidula dilatata and Nucella crassilabrum. Int J Invertebr Reprod Dev 11:239-254

> Gosselin LA, Rehak R (2007) Initial juvenile size and environmental severity: influence of predation and wave exposure on hatchling size in Nucella ostrina. Mar Ecol Prog Ser 339:143-155

Hohenlohe P (2003) Distribution of sister Littorina species, I. Tenacity and the wave-exposure gradient. Veliger 46 : 162-168

Hollander J, Butlin RK (2010) The adaptive value of phenotypic plasticity in two ecotypes of a marine gastropod. BMC Evol Biol 10:333

Hughes RN, Elner WR (1979) Tactics of a predator, Carcinus maenas, and morphological responses of the prey, Nucella lapillus. J Anim Ecol 48:65-78

> Ito K (1997) Egg-size and -number variations related to maternal size and age, and the relationship between egg size and larval characteristics in an annual marine gastropod, Haloa japonica (Opisthobranchia; Cephalaspidea). Mar Ecol Prog Ser 152:187-195

> Johannesson K, Johannesson B, Rolán-Alvarez E (1993) 
Morphological differentiation and genetic cohesiveness over a microenvironmental gradient in the marine snail Littorina saxatilis. Evolution 47:1770-1787

Johannesson B, Johannesson K (1996) Population differences in behaviour and morphology in the snail Littorina saxatilis: phenotypic plasticity or genetic differentiation. Zoology 240:475-493

Lardies MA, Fernández M (2002) Effect on oxygen availability in determining clutch size in Acanthina monodon. Mar Ecol Prog Ser 239:139-146

Leroy F, Comtet T, Brante A, Leroux C, Riera P (2012) Can encapsulated embryos of Crepidula fornicata (L.) use extracapsular dissolved organic matter? An experimental study with a ${ }^{13} \mathrm{C}$-enriched amino acid. J Molluscan Stud 78:100-104

Márquez F, Nieto Vilela RA, Lozada M, Bigatti G (2015) Morphological and behavioral differences in the gastropod Trophon geversianus associated to distinct environmental conditions, as revealed by a multidisciplinary approach. J Sea Res 95:239-247

Miller LP, O'Donnell MJ, Mach KJ (2007) Dislodged but not dead: survivorship of a high intertidal snail following wave dislodgement. J Mar Biol Assoc UK 87:735-739

Miner BG, Donovan DA, Andrews KE (2010) Should I stay or should I go: predator-and conspecific-induced hatching in a marine snail. Oecologia 163:69-78

Moran AL, Emlet RB (2001) Offspring size and performance in variable environments: field studies on a marine snail. Ecology 82:1597-1612

Navarrete SA, Castilla JC (1990) Resource partitioning between intertidal predatory crabs: interference and refuge utilization. J Exp Mar Biol Ecol 143:101-129

Pascoal S, Carvalho G, Creer S, Rock J, Kawaii K (2012) Plastic and heritable components of phenotypic variation in Nucella lapillus: an assessment using reciprocal transplant and common garden experiments. PLoS ONE 7: e30289

Reid DG, Osorio C (2000) The shallow-water marine Mollusca of the Estero Elefantes and Laguna San Rafael, southern Chile. Bull Nat Hist Mus Lond (Zool) 66:109-146

Rohlf FJ (2005a) Geometric morphometrics simplified. Trends Ecol Evol 20:13-14

Rohlf FJ (2005b) TpsDig2 2.04. Available at: http://life.bio.

Editorial responsibility: Romuald Lipcius, Gloucester Point, Virginia, USA sunysb.edu/morph/

Rohlf FJ (2005c) TpsRelw 1.41. Available at: http://life.bio. sunysb.edu/morph/

Sánchez R, Sepúlveda RD, Brante A, Cárdenas L (2011) Spatial pattern of genetic and morphological diversity in the direct developer Acanthina monodon (Gastropoda: Mollusca). Mar Ecol Prog Ser 434:121-131

Sepúlveda RD, Ibáñez CM (2012) Clinal variation in the shell morphology of intertidal snail Acanthina monodon in the southeastern Pacific Ocean. Mar Biol Res 8: 363-372

Sepúlveda RD, Jara CG, Gallardo CS (2012) Morphological analysis of two sympatric ecotypes and predator-induced phenotypic plasticity in Acanthina monodon (Gastropoda: Muricidae). J Molluscan Stud 78:173-178

Solas MR, Sepúlveda RD, Brante A (2013) Genetic variation of the shell morphology in Acanthina monodon (Gastropoda) in habitats with different wave exposure conditions. Aquat Biol 18:253-260

> Spight TM (1976) Hatching size and the distribution of nurse eggs among prosobranch embryos. Biol Bull (Woods Hole) 150:491-499

> Thiel M, Dernedde T (1994) Recruitment of shore crabs (Carcinus maenas) on tidal flats: mussel clumps as an important refuge for juveniles. Helgol Meerersunters 48: 321-332

> Trussell GC (1997) Phenotypic plasticity in the foot size of an intertidal snail. Ecology 78:1033-1048

Trussell GC, Nicklin MO (2002) Cue sensitivity, inducible defense, and trade-offs in a marine snail. Ecology 83: 1635-1647

> Vaughn D (2007) Predator-induced morphological defenses in marine zooplankton: a larval case study. Ecology 88: 1030-1039

- Warkentin KM (1995) Adaptive plasticity in hatching age: a response to predation risk trade-offs. Proc Natl Acad Sci USA 92:3507-3510

> Warkentin KM (2005) How do embryos assess risk? Vibrational cues in predator-induced hatching of red-eyed treefrogs. Anim Behav 70:59-71

Zelditch ML, Swiderski DL, Sheets HD, Fink WL (2004) Geometric morphometrics for biologists. Elsevier Academic Press, New York, NY

Submitted: October 2, 2014; Accepted: January 26, 2015 Proofs received from author(s): April 20, 2015 